\title{
Complications in Hip Arthroscopy
}

\author{
Naoki Nakano \\ Vikas Khanduja
}

Department of Trauma and Orthopaedics, Addenbrooke's, Cambridge University Hospitals NHS Foundation Trust, Cambridge, UK

\section{Corresponding author:}

Mr. Vikas Khanduja MD

Consultant Orthopaedic Surgeon \& Associate

Lecturer

Department of Trauma and Orthopaedics,

Addenbrooke's, Cambridge University Hospitals NHS Foundation Trust. Box 37, Hills Road, Cambridge, CB2 OQQ, UK

Tel: +44 (0) 1223257093

Fax: +44 (0) 1223317207

Email:vk279@cam.ac.uk

\section{Summary}

Background: Recent developments in hip arthroscopic techniques and technology have made it possible in many cases to avoid open surgical dislocation for treating a variety of pathology in the hip. Although early reports suggest favourable results' using hip arthroscopy and it has been shown to be a relatively safe procedure, complications do exist and can sometimes lead to significant morbidity.

Methods: This is a review article. The aim of this manuscript is to present the most frequent and/or serious complications that could occur at or following hip arthroscopy and some guidelines to avoid these complications.

Conclusion: Most complications of hip arthroscopy are minor or transient but serious complications can occur as well. A lot of complication e.g. acetabular labral puncture go unreported. Appropriate education and training, precise and meticulous surgical technique with correct instrumentation, the right indication in the right patient and adherence to advice from mentors and experienced colleagues are all essential factors for a successful outcome. Level of evidence: $\mathrm{V}$.

KEY WORDS: hip, arthroscopy, complication, intra-operative complications, post-operative complications, preventing complications, review.

\section{Introduction}

Hip arthroscopy as a surgical technique has evolved significantly over the last decade ${ }^{1}$ for the treatment of many articular and peri-articular pathologies ${ }^{2}$. And in doing so, the indications, both diagnostic and therapeutic, have expanded as well ${ }^{3,4}$. Although hip arthroscopy has been shown to be a relatively safe procedure with a lower rate of complications in comparison with open surgery of the hip joint ${ }^{5}$, it is still considered a technically more demanding procedure because of the anatomical nature of the joint. The hip is a fairly deep-seated joint and is stabilised statically by the deep acetabulum and the acetabular labrum and dynamically by the thick muscular envelope (of over 17 muscles) surrounding the joint ${ }^{6,7}$. In addition to these innate anatomical factors, the need for joint distraction and the use of specially designed instrumentation add to the technical complexity of the procedure, and overcoming these difficulties bears the risk of a variety of potential complications ${ }^{8-10}$.

The rate of complications associated with hip arthroscopy is variable in the literature and ranges from around $1^{11,12}$ to $8 \%{ }^{13,14}$. Kowalczuk et al. reported that the overall complication rate was $4.0 \%$ (95\% $\mathrm{Cl} 2.9-5.2 \%$ ) from a systematic review and metaanalysis of 6962 cases, and the majority of complications were non-life or limb threatening in nature ${ }^{10}$. Differences in patient selection, indications and the definition of a specific complication could potentially be responsible for these variations amongst different studies.

The aim of this article, therefore, is to present an overview of all the potential complications that are associated with arthroscopic procedures in and around the hip joint and to also present some specific guidelines, which would avoid these complications. For the ease of presentation, we have divided the complication into intra-operative, early post-operative and late post-operative (Table I).

\section{Intra-operative Complications}

\section{Injury to the Acetabular Labrum and Articular Cartilage}

Injury to the articular cartilage and the acetabular labrum is relatively common in hip arthroscopy. Typically, the superior or anterosuperior labrum is at risk of inadvertent puncture when the surgeon is trying to establish the anterolateral portal. The part of the 
Table I. Potential complications that are associated with arthroscopic procedures in and around the hip joint.

Intra-operative Complications
Injury to the Acetabular Labrum and Articular Cartilage
Injury to the Neurovascular Structures
Injuries Secondary to Traction
Inadequate Osseous Reshaping
Chondral Damage due to Misplaced Anchors
Fluid Extravasation
Hypothermia

Early Post-operative Complications

Infection

Deep Vein Thrombosis (DVT)

Instability

Late Post-operative Complications

Avascular Necrosis of the Femoral Head

Adhesions

Heterotopic Ossification

Femoral Neck Fracture

Trochanteric Bursitis and Iliopsoas Tendinitis

labrum corresponding to the anterior portal may also be injured when visualisation is poor, for example, in the presence of moderate to severe synovitis. In patients with dysplasia, although the hip is easily distracted, the labrum is hypertrophied and easily punctured whilst gaining access to the joint. This problem is accentuated when the labrum is detached from the acetabulum and is occupying more of the joint space. As far as the injury to the articular cartilage is concerned, scuffing usually takes place on the femoral head $^{15}$. Insufficient traction has traditionally been reported as the main cause of these injuries ${ }^{12,16}$. latrogenic injury to the femoral head may also occur in complex cases, which require repetitive exchange of instruments rendering the femoral head at risk of damage from the rigid metal instrumentation even though the joint has enough distraction.

Surgeons are recommended to briefly exchange portals with the camera, in order to check that the labrum has not been punctured by the cannula. Also, a distraction $>10 \mathrm{~mm}$ followed by intra-articular injection of $20 \mathrm{ml}$ or above of normal saline for fluid distension is advised for safe access to the hip joint. If adequate distraction cannot be achieved, it is recommended that the peripheral compartment be accessed first, to allow for placement of the guide wire into the central compartment under direct vision with the camera ${ }^{15}$.

Finally, it is difficult to put a percentage on the risk of injuring the acetabular labrum and articular cartilage as these have not been reported widely in the literature but it is not inconceivable to imagine that the risk of injuring these structures is fairly high especially in the hands of the novice.

\section{Injury to the Neurovascular Structures}

The hip joint is surrounded by several neurovascular structures: the femoral neurovascular bundle anteriorly, the lateral femoral cutaneous nerve antero-laterally and the sciatic nerve and gluteal vessels posteriorly ${ }^{17}$. Direct injury to the neurovascular bundle is very rare, although great care is needed to avoid this potentially devastating complication².

As far as vascular injuries are concerned, Griffin and Villar ${ }^{18}$ describe a case of bleeding from an arthroscopic portal with injury to a superficial vein, which ceased after 48 hours of external pressure. As osteoplasty of the proximal femur for treatment of cam-type femoroacetabular impingement (FAI) involves exposure of a relatively large surface area of highly vascular cancellous bone, minor intra-operative bleeding is commonly encountered. One has to be aware of the proximity of the medial circumflex femoral vessels and its branches when performing an osteoplasty laterally or release of the iliopsoas from the peripheral compartment ${ }^{19}$.

Penetration injury to the nerves around the hip joint at hip arthroscopy is rare and most nerve injuries are secondary to traction. However, damage to the lateral femoral cutaneous nerve has been reported because of poor portal placement. Its incidence is difficult to define, as it is not always clear whether reported cases are due to traction neurapraxia or direct damage $^{15,20}$.

Bony landmarks such as the anterior superior iliac spine and borders of the greater trochanter should always be identified and marked. Also, the skin incision should not extend into the subcutaneous fat because the lateral femoral cutaneous nerve runs quite superficially.

\section{Injuries Secondary to Traction}

Effective distraction is needed to provide adequate exposure of the hip joint to comprehensively assess intra-articular pathology and for accommodation of appropriate arthroscopic instrumentation ${ }^{21}$. Distraction techniques typically employ traction tables or surgical distractors that apply an axial force down the entire lower extremity along with the perineal post acting as a lever22. This can lead to soft-tissue injuries associated with the traction itself (distractiontype) or with the perineal post (compression-type).

The most commonly cited complication following hip arthroscopy is a distraction-type injury, occurring in up to $7 \%$ of the $\operatorname{cases}^{23,24}$. These often present as neurapraxias of the femoral, sciatic, or peroneal nerves due to an excessive traction force or a prolonged traction time ${ }^{25,26}$. Recent improvements in surgical techniques and development of specialised hip distractors have led to a decrease in the incidence of these injuries. For prevention of these injuries, surgeons should try to limit the traction forces to $<50 \mathrm{lbs}$ $(22.7 \mathrm{~kg})$ in most cases ${ }^{22}$. In addition, the continuous 


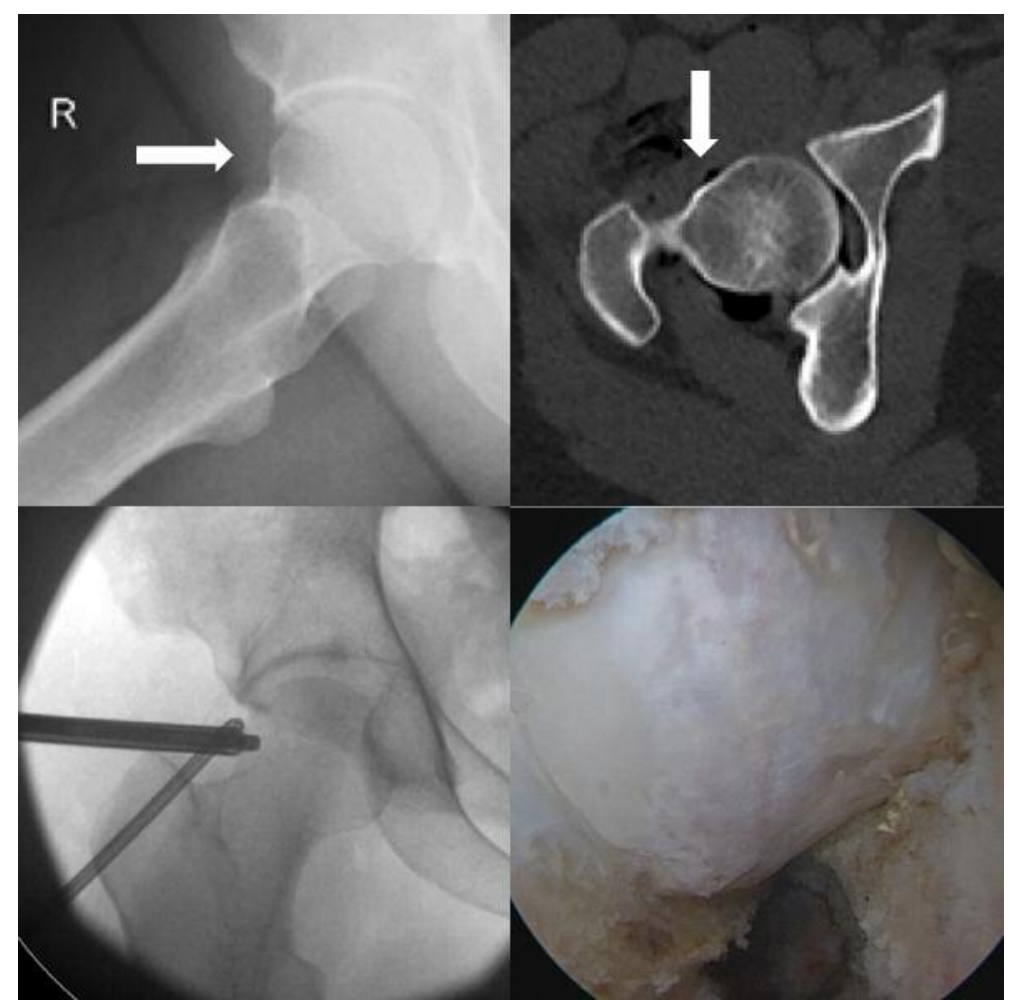

Figure 1. Incomplete shaving. The arrows show the residual bump deformity. Lower right: Intraoperative image of the bump.

traction time should not exceed two hours, as a guideline for minimising the risk of neurapraxias ${ }^{26}$. Griffin et al. ${ }^{18}$ have proposed a 'trial of traction' prior to the procedure to minimise the duration of continuous traction. This involves applying traction temporarily to ensure the hip is distractible, then releasing traction during the preparation and draping of the operative field, and then re-applying it when the operation commences.

Compression-type injuries are associated with the compressive force, usually exerted by the perineal post. They are localised in the area of the groin where the pudental nerve is at risk. In fact, pudental nerve injuries have been reported since the first descriptions of hip arthroscopy ${ }^{27}$. Other soft tissue injuries that may occur secondary to compression include injury to the scrotum and the labia major, and this could range from a small hematoma ${ }^{28}$ or oede$\mathrm{ma}^{29}$ to full blown pressure necrosis ${ }^{29-31}$. Prevention of compression-type injuries requires a heavily padded post, which is wide enough (diameter $>9 \mathrm{~cm}$ ) to distribute the forces over a larger area of the skin. This post should ideally be positioned against the medial thigh in abduction which allows it to act as a lever, not the genitalia or groin crease ${ }^{2,32}$.

\section{Inadequate Osseous Reshaping}

Inadequate reshaping of the cam and pincer lesions is a newly recognised complication affecting outcomes following arthroscopic surgery. It is increasing in frequency along with the growing number of hip arthroscopies being performed worldwide and is the commonest indication for revision hip arthroscopy (Figure 1). Philippon et al. ${ }^{33}$ reported that $92 \%$ out of 37 revision cases had inadequate resection of their cam or pincer lesions. In another series of 24 patients investigating the causes and outcomes of revision hip arthroscopy, 79\% (19 cases) of their patients had inadequate or no osseous reshaping ${ }^{34}$.

Avoiding inadequate reshaping and for achieving complete resection, it is essential to comprehend the pre-operative deformity. Imaging techniques such as 3D-CT, MR arthrography and collision detection software from Clinical Graphics are powerful tools that help surgeons to understand the shape of the deformity and also the point of collision ${ }^{35-37}$. Using intraoperative image intensifier in planning and verifying adequacy of bony resection is also essential and strongly advised ${ }^{38,39}$.

\section{Chondral Damage due to Misplaced Anchors}

Suture anchors are used for fixation of soft tissues to bone. In order to restore labral function including the labral fluid seal effect, the fixation device should be placed on the acetabular rim close to, but not damaging the articular cartilage or joint ${ }^{40,41}$. Suture anchors placed too far from the articular cartilage can evert or medialises the labrum and compromise its function, while anchors placed too close to the articular cartilage can cause iatrogenic cartilage injury. From a multicentre retrospective case series ${ }^{42}$, the 1 o'clock position and anterior/mid-anterior portals were most commonly implicated.

To prevent this serious complication, surgeons 
should be aware that the distal anterolateral accessory (DALA) portal allows anchors to be placed at a greater distance from the articular surface than the anterolateral $(A L)$ and mid-anterior (MA) portals when using a straight drill guide ${ }^{43}$. This may decrease the incidence of intra-articular penetration during arthroscopic hip labral repair. Other preventative measures may include use of small diameter and short anchors, removable hard anchors, soft suture-based anchors, curved drills and anchor insertion instrumentation and attention to safe trajectories while visualising the acetabular articular surface ${ }^{42}$.

\section{Fluid Extravasation}

Fluid extravasation, in other words, leakage of the irrigation fluid into anatomical spaces adjacent to the joint, is a serious complication of hip arthroscopy. Although most reported cases involve extra-capsular endoscopic procedures (typically release of the psoas tendon $)^{44-46}$, the fluid can also escape through capsular incisions especially following large capsulotomies at intra-articular hip arthroscopy 47,48 . Another factor, which has been linked with fluid extravasation, is increase in the surgical time of the procedure ${ }^{44,47}$.

Fluid can also escape into the abdominal cavity and retroperitoneum and if it is more than $2 \mathrm{~L}$ this becomes symptomatic and can have serious consequences ${ }^{47}$. In cases performed under general anaesthesia, continued accumulation of abdominal fluid may lead to compartment syndrome and a case of cardiac arrest ${ }^{49}$ has also been reported following extravasation into the abdominal cavity. Diagnosis in these cases is confirmed with a CT 46,48 or ultrasound 47 and an urgent general surgical consult is advised.

The procedure should be abandoned if there are signs of extravasation threatening the patient's general condition. Also, intra-operatively, the abdomen and core body temperature should be closely monitored. In addition, surgical time should be kept to a minimum and inflow fluid pressure should be low (maximum $50 \mathrm{mmHg}$ ). Fluid extravasation should be discussed with all the patients undergoing hip arthroscopy, and should always feature on the consent forms ${ }^{48}$.

\section{Hypothermia}

Hypothermia is a decrease in core body temperature below $35^{\circ} \mathrm{C}\left(95^{\circ} \mathrm{F}\right)$. Intraoperative hypothermia alters tissue regeneration capacity and increases the risk of post-operative infections. It also promotes bleeding by causing alterations in platelet activity and the coagulation cascade 50,51 . Parodi et al. ${ }^{52}$ reported that the incidence of hypothermia in patients who underwent hip arthroscopy for the treatment of FAI was $2.7 \%$, and the factors that contribute towards the development of hypothermia during hip arthroscopic surgery were prolonged surgical time, low BMI, low blood pressure during the procedure, and low temperature of the arthroscopic irrigation fluid.

To prevent hypothermia during hip arthroscopy, appropriate use of warming blanket and warming the arthroscopic irrigation fluid are recommended ${ }^{53}$.

\section{Early Post-operative Complications}

\section{Infection}

Procedure times can vary significantly but hip arthroscopy usually takes anything between 45 minutes to 150 minutes to perform and involves extensive soft-tissue dissection, bony reshaping and the use of foreign material (e.g. implants for labral fixation, sutures for capsular plication). Additionally, it is sometimes performed in the presence of a hip replacement for iliopsoas release or diagnosing undefined pain in a THR. All these factors and more could potentially lead to an infection following hip arthroscopy but the incidence is low. Only one case of septic arthritis following hip arthroscopy has been report$\mathrm{ed}^{12}$, and another case of a suture abscess in a proximal portal of a patient undergoing arthroscopy for Perthes' disease has been reported as well ${ }^{54}$.

Chemoprophylaxis in hip arthroscopy has not been closely studied. To the best of our knowledge, there are no specific recommendations, which are universally accepted. In our practice, we use a single intravenous dose of a broad-spectrum antibiotic at induction and repeat the dose if the procedure time is over 120 minutes.

\section{Deep Vein Thrombosis (DVT)}

In a retrospective review of 81 cases of hip arthroscopy, three patients (3.7\%) developed symptomatic DVT post-operatively confirmed by Doppler ultrasound ${ }^{55}$. Another retrospective study of 35 hip arthroscopies revealed only one case of DVT, although femoral osteoplasty in those patients was performed through a limited open approach ${ }^{56}$. The true incidence of DVT following hip arthroscopy seems to be either under-reported or unrecognised. Again like infection, there are no formal guidelines on the type, duration and need of thromboprophylaxis following hip arthroscopy. More research is needed to clarify the pathology and the best course of management. In our practice, the senior Author administers pharmacological prophylaxis on an individualised basis depending on predisposing risk factors (e.g. age, family or personal history of DVT or PE, obesity, smoking), early post-operative mobilisation and the nature of the procedure (e.g. microfracture). However, mechanical thromboprophylasis in the form of calf compression on the opposite calf intra-operatively and below-knee elastic thromboembolic deterrent stockings for 6 weeks post-operatively are recommended for every patient for prevention of this complication.

\section{Instability}

Hip instability following hip arthroscopy could occur because of soft tissue laxity or inadequate bony cover and is difficult to diagnose ${ }^{57}$. There is a concern that anterior hip capsulotomy or capsulectomy may reproduce the situation of injury to the iliofemoral ligament, which results in soft tissue instability. This is a rare complication, and the few reported cases share several risk factors, including: female, age from 39 to 52 
years, early occurrence, and anterior instability $29,58-61$ In patients with demonstrable capsular laxity pre-operatively, the peripheral compartment should not be accessed through the central compartment to minimise capsular dissection, or the capsule should be repaired following the procedure.

Bony hip instability also may develop in relation to excessive bone removal from the acetabular rim in addressing the pincer impingement. Different from soft tissue instability, excessive bone resection from the anterior acetabular rim may result in anterior hip dislocation. Risk factors for post-operative bony instability, including a centre-edge angle $<25^{\circ}$, primary hyper laxity, and previous episodes of traumatic instability, and all these factors must be identified pre-operatively. Rim recession should be avoided in patients who have a centre-edge angle of $20^{\circ}$ or less as measured on the antero-posterior radiograph of the pelvis. Bony instability is a devastating complication, which is fairly difficult to address and the patient may require further surgical procedures like a total hip replacement or a reverse periacetabular osteotomy to abolish symptoms.

\section{Late Post-operative Complications}

\section{Avascular Necrosis of the Femoral Head}

Avascular necrosis after hip arthroscopy is more of a hypothetical concern than an actual clinical problem. No cases of avascular necrosis have been reported in relation with arthroscopic reshaping of FAI. Sampson et al. ${ }^{62}$ reported one case of avascular necrosis in a series of 1,000 consecutive hip arthroscopies. It occurred 7 months after a partial labral resection and debridement for osteoarthritis due to an injury at work. They mentioned that although the hip might have been already at risk by the original injury, the distraction and partial capsulectomy might have also contributed to the necrosis.

At arthroscopy, the blood supply is most at risk when reshaping of the cam FAI lesion is performed. The medial femoral circumflex artery, which is critical for the vascularity of the femoral head ${ }^{63}$, enters the hip capsule at the level of the superior gemellus and gives rise to two to four intracapsular superior or lateral retinacular vessels ${ }^{37}$. Factors linked to avascular necrosis of the femoral head after hip arthroscopy include distraction, partial capsulectomy and damage to the lateral epiphyseal branch of the medial femoral circumflex artery. Extreme caution should therefore be exercised, when capsular dissection or bony resection, posterior to the lateral synovial fold in the peripheral compartment is being carried out.

\section{Adhesions}

Adhesions following hip arthroscopy tend to develop between the capsular side of the labrum and the capsule especially after labral repair and rim recession. They could also develop in the peripheral compartment between the femoral neck and the capsule following osteoplasty ${ }^{64}$. Adhesions can become symptomatic by impairing the sealing function of the labrum or by impinging against it. Patients usually present with groin pain and restricted flexion and rotation. MR arthrography is the most useful tool in aiding the diagnosis of this complication but it requires a high index of suspicion ${ }^{65}$. The pathophysiology of adhesions following hip arthroscopy has not been studied in detail, but post-operative continuous passive movement may be helpful. Also, post-operative range of movement exercises, like the use of a stationary bicycle without resistance, should be commenced as soon as pain allows post-operatively.

\section{Heterotopic Ossification}

The incidence of heterotopic ossification following hip arthroscopy appears to have increased as a result of the development of arthroscopic techniques for FAI and larger capsulotomies. An incidence of $1.6 \%$ in 300 cases of hip arthroscopy for FAI has been reported, with no post-operative prophylaxis against heterotopic ossification 66 . It is theorised that surgical trauma to the gluteal muscles and the bone debris generated during osteoplasty in the treatment of FAI might trigger the formation of new bone. Heterotopic ossification following arthroscopy has usually not known to cause a functional problem.

Prevention of this complication requires the hip joint to be lavaged carefully at the end of procedure to ensure that all the bony debris from the osteoplasty has been cleared 67 . Secondly prophylaxis with Indomethacin or naproxen ${ }^{68}$ should be considered for 4-6 weeks and the surgeon should ensure that the large capsulotomies are sutured following the procedure ${ }^{69}$. Finally, all the patients should be followed-up (range of movement and radiograph) for up to 12 months if heterotopic ossification does appear on the first post-operative radiograph.

\section{Femoral Neck Fracture}

Over enthusiastic resection of the femoral neck associated with the treatment of cam-type FAI can potentially lead to a fracture and is a cause for concern. Since, the arthroscopic field of view limits visualisation of the femoral head-neck junction, a complete examination with the arthroscope from different portals is essential to comprehend the exact shape and size of the cam deformity. The medial, lateral, superior, and inferior edges of the deformity should be clearly identified prior to commencing resection.

Mardones et al. ${ }^{70}$ in a cadaveric study suggested that $30 \%$ of the femoral neck diameter could be resected safely without the risk of a fracture. The resection undertaken in removal of the cam-type deformity is usually to the depth of the normal neck profile, which rarely reaches $30 \%$ of the neck diameter ${ }^{8}$.

The patient's age, bone quality, the amount of bone resected and the level of post-operative weight bearing are factors, which are thought to contribute to this complication. Osseous remodelling at the site of the femoral head-neck junction after osteoplasty has been well-described in 113 hips undergoing a limited open procedure with toe-touch weight-bearing for six weeks ${ }^{71}$. Most researchers agree that partial weight 
bearing should be indicated during the first 6 post-operative weeks after an arthroscopic reshaping for the cam-type $\mathrm{FAl}^{72,73}$. Moreover, surgeons should be mindful of the fact that the burr has to be handled gently and bony indentations, which may act as stress risers should be avoided.

\section{Trochanteric Bursitis and Iliopsoas Tendinitis}

Trochanteric bursitis can be caused by any previous surgery around the hip joint. There has been a report of one case of trochanteric bursitis several weeks following arthroscopy which was treated by an injection of local anaesthetic and steroid into the bursa ${ }^{18}$. This may have occurred because of repeated punctures of the bursa with the arthroscopic needle or altered gait biomechanics.

Iliopsoas tendinitis could also occur via the same mechanism, although currently there have been no cases reported in the literature.

\section{Complications in Children}

Hip arthroscopy in children is technically challenging, because of a smaller body size, variable anatomy and the possible history of previous operations ${ }^{74}$. However, complications of hip arthroscopy in children are infrequent and similar to those seen in adults $^{54,75,76}$. Currently, the amount of traction and the threshold of pressure to minimise extravasation have not been investigated in depth in children. The chances for hypothermia are higher in children and therefore warm irrigation fluid should be used. Careful patient positioning is paramount ${ }^{74}$. The foot must be heavily-padded before use of the foot holder to avoid excessive pressure on the skin and nerves ${ }^{77}$, and manual traction alone may be needed in very young children with hip dysplasia ${ }^{78,79}$. Arthroscopic portals may have to be modified and the use of smaller instrumentation is advised. Parents must be informed that, depending on the primary condition, hip arthroscopic treatment may not be as effective and further operations may well be necessary (most commonly osteotomies for dysplasia) ${ }^{74}$.

\section{Does Previous Hip Arthroscopy Negatively Affect the Clinical Results of Total Hip Replacement (THR)?}

The risk that hip arthroscopy may negatively influence the outcome of a subsequent THR remains to be another concern. Whilst there is enough evidence in the literature to support the use of arthroscopy for $\mathrm{FAI}$, there is conflicting evidence regarding hip arthroscopy for the treatment of mild and moderate osteoarthritis ${ }^{80}$. From a morphological point of view, hip arthroscopy does not seem to make a subsequent THR more difficult, but potential scarring and persistent post-operative inflammation could theoretically negatively influence the outcome of the THR. Such a negative influence on the performance and the out- come of THR could potentially be important in clarifying the indications for hip arthroscopy, particularly in patients who have already developed moderate arthritic changes in their joint.

Although Haughom et al. ${ }^{81}$ have reported that patients without previous hip arthroscopy demonstrated a greater overall improvement (not statistically significant) after THR than patients with previous hip arthroscopy with regard to Harris Hip Score, there has been no clear evidence that previous hip arthroscopy negatively influences the performance or short term clinical outcome of a $\mathrm{THR}^{82}$.

\section{How to Minimise Complications in Hip Arthroscopy?}

Hip Arthroscopy is a relatively safe procedure and most complications are preventable. Any surgeon wishing to embark on a career in hip preservation surgery should receive appropriate education in the form of a fellowship, a cadaver-training programme and ideally a mentor who is available for the first few procedures. A precise surgical technique, appropriate instrumentation and adherence to advice from experienced colleagues are all essential factors for a successful outcome.

Common tips for preventing complications include:

- Continuous traction should not exceed two hours. Intermittent traction should be used if needed.

- The traction force should be limited to $22.7 \mathrm{~kg}$ (50 Ibs).

- The perineal post and foot plate/boot must be heavily padded with soft material.

- The extremity should be positioned correctly in slight abduction and flexion.

- Distraction should not be less than $10 \mathrm{~mm}$.

- The joint should then be distended with $20 \mathrm{ml}$ of normal saline and the labral silhouette seen for safe access into the joint.

- Inflow fluid pressure should be low (up to 50 $\mathrm{mmHg}$ ).

- Post-operative range of movement exercises should be initiated as soon as pain allows.

- Pharmacological prophylaxis should be administered on an individualised basis to prevent infection heterotopic ossification and DVT.

- Minimise capsular dissection in patients with demonstrable capsular laxity.

- A centre-edge angle less than $20^{\circ}$ is a contraindication for acetabular rim trimming.

- The osseous deformity should be exposed adequately before resection.

\section{Conclusion}

Hip arthroscopy is a surgical procedure that makes it possible to approach the hip joint in a minimally invasive manner and has revolutionised the treatment of many intra and extra-articular conditions. However, it is highly operator dependent, not for the occasional 
operator and certainly not without complications. As might be expected, the correct indication in a well-selected cohort of patients and a well-trained and experienced surgeon with knowledge of the problems described in the article and tips of avoiding them are essential to diminish the rate of complications following this procedure.

The Authors declare that this mini-review was conduct according ethically to international standards and as required by the journal as described ${ }^{83}$.

\section{Ethics}

We followed basic ethical aspects and international laws described by Muscles, Ligaments and Tendons Journal ${ }^{83}$.

\section{References}

1. Colvin AC, J. Harrast J, Harner C, Trends in hip arthroscopy. J Bone Joint Surg Am. 2012;94(4):p.e23.

2. Byrd JW, Hip arthroscopy: surgical indications. Arthroscopy. 2006;22(12):p.1260-2.

3. Glick JM, F. Valone 3rd, Safran MR. Hip arthroscopy: from the beginning to the future-an innovator's perspective. Knee Surg Sports Traumatol Arthrosc. 2014;22(4):p.714-21.

4. Lynch TS, et al. Hip arthroscopic surgery: patient evaluation, current indications, and outcomes. Am J Sports Med. 2013; 41(5):p.1174-89.

5. Clohisy JC, St John LC, Schutz AL. Surgical treatment of femoroacetabular impingement: a systematic review of the literature. Clin Orthop Relat Res. 2010;468(2):p.555-64.

6. Khanduja V, Villar RN. Arthroscopic surgery of the hip: current concepts and recent advances. J Bone Joint Surg Br. 2006; 88(12):p.1557-66.

7. Mei-Dan O, Young DA. A Novel Technique for Capsular Repair and Labrum Refixation in Hip Arthroscopy Using the SpeedStitch. Arthrosc Tech. 2012;1(1):p.e107-12.

8. Ilizaliturri VM, Jr. Complications of arthroscopic femoroacetabular impingement treatment: a review. Clin Orthop Relat Res. 2009;467(3):p.760-8.

9. Konan S, Rhee SJ, Haddad FS. Hip arthroscopy: analysis of a single surgeon's learning experience. J Bone Joint Surg Am. 2011;93;Suppl 2:p.52-6.

10. Kowalczuk M, et al. Complications following hip arthroscopy: a systematic review and meta-analysis. Knee Surg Sports Traumatol Arthrosc. 2013;21(7):p.1669-75.

11. Byrd JW. Hip arthroscopy. The supine position. Clin Sports Med. 2001;20(4):p.703-31.

12. Clarke MT, Arora A, Villar RN. Hip arthroscopy: complications in 1054 cases. Clin Orthop Relat Res. 2003(406):p.84-8.

13. Harris JD, et al. Complications and reoperations during and after hip arthroscopy: a systematic review of 92 studies and more than 6,000 patients. Arthroscopy. 2013;29(3):p.589-95.

14. Larson CM, Giveans MR, Taylor M. Does arthroscopic FAI correction improve function with radiographic arthritis? Clin Orthop Relat Res. 2011;469(6):p.1667-76.

15. Dienst M, et al. Hip arthroscopy without traction: In vivo anatomy of the peripheral hip joint cavity. Arthroscopy. 2001; 17(9):p.924-31.

16. McCarthy JC, Lee JA. Hip arthroscopy: indications, outcomes, and complications. Instr Course Lect. 2006;55:p.301-8.

17. McCarthy JC. Hip Arthroscopy: Applications and Technique. J Am Acad Orthop Surg. 1995;3(3):p.115-122.
18. Griffin DR, Villar RN. Complications of arthroscopy of the hip. J Bone Joint Surg Br. 1999;81(4):p.604-6.

19. Lazaro LE, et al. The terminal branches of the medial femoral circumflex artery: the arterial supply of the femoral head. Bone Joint J. 2015;97-B(9):p.1204-13.

20. Byrd JW, Jones KS. Prospective analysis of hip arthroscopy with 10-year followup. Clin Orthop Relat Res. 2010;468 (3):p.741-6.

21. Flecher X, Dumas J, Argenson JN. Is a hip distractor useful in the arthroscopic treatment of femoroacetabular impingement? Orthop Traumatol Surg Res. 2011;97(4):p.381-8.

22. Papavasiliou AV, Bardakos NV. Complications of arthroscopic surgery of the hip. Bone Joint Res. 2012;1(7): p.131-44.

23. Simpson J, Sadri H, Villar R. Hip arthroscopy technique and complications. Orthop Traumatol Surg Res. 2010;96(8 Suppl):p.S68-76.

24. Lo YP, et al. Complications of hip arthroscopy: analysis of seventy three cases. Chang Gung Med J. 2006;29(1):p.86-92.

25. Martin HD, et al. Physiological changes as a result of hip arthroscopy performed with traction. Arthroscopy. 2012;28 (10):p.1365-72.

26. Flierl MA, et al. Traction table-related complications in orthopaedic surgery. J Am Acad Orthop Surg. 2010;18(11): p.668-75.

27. Glick JM, et al. Hip arthroscopy by the lateral approach. Arthroscopy. 1987;3(1):p.4-12.

28. Funke EL, Munzinger U. Complications in hip arthroscopy Arthroscopy. 1996;12(2):p.156-9.

29. Souza BG, et al. Do complications in hip arthroscopy change with experience? Arthroscopy. 2010;26(8):p.1053-7.

30. Eriksson E, Arvidsson I, Arvidsson H. Diagnostic and operative arthroscopy of the hip. Orthopedics. 1986;9(2): p.169-76.

31. Gedouin JE, et al. Assessment of arthroscopic management of femoroacetabular impingement. A prospective multicenter study. Orthop Traumatol Surg Res. 2010;96(8 Suppl):p.S5967.

32. Smart LR, et al. Beginning hip arthroscopy: indications, positioning, portals, basic techniques, and complications. Arthroscopy. 2007;23(12):p.1348-53.

33. Philippon MJ, et al. Revision hip arthroscopy. Am J Sports Med. 2007;35(11):p.1918-21.

34. Heyworth BE, et al. Radiologic and intraoperative findings in revision hip arthroscopy. Arthroscopy. 2007;23(12):p.1295302.

35. Ganz R, et al. The etiology of osteoarthritis of the hip: an integrated mechanical concept. Clin Orthop Relat Res. 2008; 466(2):p.264-72.

36. Ganz R, et al. Femoroacetabular impingement: a cause for osteoarthritis of the hip. Clin Orthop Relat Res. 2003(417): p.11220.

37. Gautier E, et al. Anatomy of the medial femoral circumflex artery and its surgical implications. J Bone Joint Surg Br. 2000;82(5):p.679-83.

38. Larson CM, Wulf CA. Intraoperative fluoroscopy for evaluation of bony resection during arthroscopic management of femoroacetabular impingement in the supine position. Arthroscopy. 2009;25(10):p.1183-92.

39. Matsuda DK. Fluoroscopic templating technique for precision arthroscopic rim trimming. Arthroscopy. 2009;25(10):p.117582.

40. Kelly BT, et al. Arthroscopic labral repair in the hip: surgical technique and review of the literature. Arthroscopy. 2005;21 (12):p.1496-504

41. Philippon MJ, Schroder BG, e Souza, Briggs KK. Labrum: resection, repair and reconstruction sports medicine and arthroscopy review. Sports Med Arthrosc. 2010;18(2): p.7682.

42. Matsuda DK, et al. Anchor-induced chondral damage in the 
hip. J Hip Preserv Surg. 2015;2(1):p.56-64.

43. Stanton M, Banffy M. Safe Angle of Anchor Insertion for Labral Repair During Hip Arthroscopy. Arthroscopy. 2016.

44. Fowler J, Owens BD. Abdominal compartment syndrome after hip arthroscopy. Arthroscopy. 2010;26(1):p.128-30.

45. Sharma A, Sachdev H, Gomillion M. Abdominal compartment syndrome during hip arthroscopy. Anaesthesia. 2009;64 (5):p.567-9.

46. Verma M, Sekiya JK. Intrathoracic fluid extravasation after hip arthroscopy. Arthroscopy. 2010;26(9 Suppl):p.S90-4.

47. Haupt $U$, et al. Intra- and retroperitoneal irrigation liquid after arthroscopy of the hip joint. Arthroscopy. 2008;24(8):p.966-8.

48. Ladner B, K. Nester, and B. Cascio, Abdominal fluid extravasation during hip arthroscopy. Arthroscopy. 2010;26(1):p.131-5.

49. Bartlett CS, et al. Cardiac arrest as a result of intraabdominal extravasation of fluid during arthroscopic removal of a loose body from the hip joint of a patient with an acetabular fracture. J Orthop Trauma. 1998;12(4):p.294-9.

50. Torossian A. Thermal management during anaesthesia and thermoregulation standards for the prevention of inadvertent perioperative hypothermia. Best Pract Res Clin Anaesthesiol. 2008;22(4):p.659-68.

51. Sessler DI. Complications and treatment of mild hypothermia. Anesthesiology. 2001;95(2):p.531-43.

52. Parodi D, et al. Hip arthroscopy and hypothermia. Arthroscopy. 2012;28(7):p.924-8.

53. Sardesai A, Hujazi I, Khanduja V. Surgical access warming blanket to prevent hypothermia after hip arthroscopy. Arthroscopy. 2012;28(8):p.1045-6; author reply 1046-7.

54. Nwachukwu BU, et al. Complications of hip arthroscopy in children and adolescents. J Pediatr Orthop. 2011;31(3):p.227-31.

55. Salvo JP, Troxell CR, Duggan DP. Incidence of venous thromboembolic disease following hip arthroscopy. Orthopedics. 2010;33(9):p.664.

56. Clohisy JC, et al. Combined hip arthroscopy and limited open osteochondroplasty for anterior femoroacetabular impingement. J Bone Joint Surg Am. 2010;92(8):p.1697-706.

57. Braly BA, Beall DP, Martin HD. Clinical examination of the athletic hip. Clin Sports Med. 2006;25(2):p.199-210, vii.

58. Benali $Y$, Katthagen BD. Hip subluxation as a complication of arthroscopic debridement. Arthroscopy. 2009;25(4):p.405-7.

59. Matsuda DK. Acute iatrogenic dislocation following hip impingement arthroscopic surgery. Arthroscopy. 2009.25(4): p.400-4.

60. Mei-Dan O, McConkey MO, Brick M. Catastrophic failure of hip arthroscopy due to iatrogenic instability: can partial division of the ligamentum teres and iliofemoral ligament cause subluxation? Arthroscopy. 2012;28(3):p.440-5.

61. Ranawat AS, McClincy M, Sekiya JK. Anterior dislocation of the hip after arthroscopy in a patient with capsular laxity of the hip. A case report. J Bone Joint Surg Am. 2009;91(1): p.192-7.

62. Sampson TG. Complications of hip arthroscopy. Clin Sports Med. 2001;20(4):p.831-5.

63. Kalhor M, et al. Capsular and pericapsular contributions to acetabular and femoral head perfusion. J Bone Joint Surg Am. 2009;91(2):p.409-18.
64. Krueger A, et al. Hip arthroscopy after previous surgical hip dislocation for femoroacetabular impingement. Arthroscopy. 2007;23(12):p.1285-1289 e1.

65. Beck M. Groin pain after open FAl surgery: the role of intraarticular adhesions. Clin Orthop Relat Res. 2009;467(3):p.769-74.

66. Randelli F, et al. Heterotopic ossifications after arthroscopic management of femoroacetabular impingement: the role of NSAID prophylaxis. J Orthop Traumatol. 2010;11(4):p.245-50.

67. Matsuda DK, Calipusan CP. Adolescent femoroacetabular impingement from malunion of the anteroinferior iliac spine apophysis treated with arthroscopic spinoplasty. Orthopedics. 201235(3):p.e460-3.

68. Beckmann JT, et al. Effect of Naproxen Prophylaxis on Heterotopic Ossification Following Hip Arthroscopy: A DoubleBlind Randomized Placebo-Controlled Trial. J Bone Joint Surg Am. 2015;97(24):p.2032-7.

69. Bedi $\mathrm{A}$, et al. The incidence of heterotopic ossification after hip arthroscopy. Am J Sports Med. 2012;40(4):p.854-63.

70. Mardones RM, et al. Surgical treatment of femoroacetabular impingement: evaluation of the effect of the size of the resection. J Bone Joint Surg Am. 2005;87(2):p.273-9.

71. Nassif NA, et al. Osseous remodeling after femoral head-neck junction osteochondroplasty. Clin Orthop Relat Res. 2010;468 (2):p.511-8

72. Guanche CA, Bare AA. Arthroscopic treatment of femoroacetabular impingement. Arthroscopy. 2006;22(1): p.95-106.

73. Ilizaliturri VM, Jr., et al. Arthroscopic treatment of cam-type femoroacetabular impingement: preliminary report at 2 years minimum follow-up. J Arthroplasty. 2008;23(2):p.226-34.

74. Jayakumar $P$, et al. Arthroscopy of the hip for paediatric and adolescent disorders: current concepts. J Bone Joint Surg Br. 2012;94(3):p.290-6.

75. Kocher MS, et al. Hip arthroscopy in children and adolescents. J Pediatr Orthop. 2005;25(5):p.680-6.

76. Schindler A, et al. Diagnostic and therapeutic arthroscopy of the hip in children and adolescents: evaluation of results. J Pediatr Orthop. 1995;15(3):p.317-21.

77. Roy DR. Arthroscopy of the hip in children and adolescents. $J$ Child Orthop. 2009;3(2):p.89-100.

78. Eberhardt O, Fernandez FF, Wirth T. Arthroscopic reduction of the dislocated hip in infants. J Bone Joint Surg Br. 2012;94 (6):p.842-7.

79. McCarthy JJ, MacEwen GD. Hip arthroscopy for the treatment of children with hip dysplasia: a preliminary report. Orthopedics. 2007;30(4):p.262-4.

80. Stevens MS, et al. The evidence for hip arthroscopy: grading the current indications. Arthroscopy. 2010;26(10):p.1370-83.

81. Haughom BD, et al. Does Hip Arthroscopy Affect the Outcomes of a Subsequent Total Hip Arthroplasty? J Arthroplasty. 2016.

82. Zingg $\mathrm{PO}$, et al. Does previous hip arthroscopy negatively influence the short term clinical result of total hip replacement? Arch Orthop Trauma Surg. 2012;132(3):p.299-303.

83. Padulo J, Oliva F, Frizziero A, Maffulli N. Muscles, Ligaments and Tendons Journal. Basic principles and recommendations in clinical and field science research: 2016 Update. MLTJ. 2016;6(1):1-5. 